\title{
Posttraumatic growth in women after breast cancer surgery - preliminary results from a study of Polish patients
}

\section{BACKGROUND}

The aim of the study was to answer the following research questions: What percentage of women after breast cancer surgery experienced posttraumatic growth (PTG)? Which aspect of PTG was experienced to the greatest extent by the participants? Do age at the day of survey, age at diagnosis, time since diagnosis, type of surgery, non-surgical methods of treatment, participation in rehabilitation or physical activity significantly differentiate participants in PTG?

\section{PARTICIPANTS AND PROCEDURE}

Forty-seven women after breast cancer surgery participated in the study. Posttraumatic growth was measured with the Polish version of the Posttraumatic Growth Inventory (PTGI) consisting of 4 scales: Self-Perception (SP), Relating to Others (RO), Appreciation of Life (AL) and Spiritual Change (SC). The demographic, disease and treatment related variables were controlled.

\section{RESULTS}

Forty-three percent of participants experienced high, 23\% moderate, and $34 \%$ little or no PTG. Posttraumatic growth manifested itself mainly positive changes in relationships with others. Age at the day of the survey did not correlate significantly with scores of PTGI. Age at diagnosis correlated significantly with total PTG $(\rho=-0.37, p=.012)$, SP $(\rho=-0.33, p=.029)$, RO $(\rho=-0.40, p=.008)$ and AL $(\rho=-0.39, p=.010)$. Women aged $\leq 50$ at the day of the survey had significantly higher scores of AL than women $>50(U=117.50, p=.042)$. Women who were physically active at the day of the survey had significantly higher scores in total PTG $(U=118.50, p=.008)$, SP $(U=7.28$, $p=.007)$ and $\mathrm{RO}(U=108.00, p=.003)$. Time since diagnosis, type of treatment and participation in rehabilitation after the surgery did not differentiate respondents significantly in PTG.

\section{CONCLUSIONS}

Posttraumatic growth was experienced by a considerable percentage of participants. The average level of PTG was moderate. Women physically active at the time of the survey showed higher levels of PTG. We recommend that women after breast cancer surgery should be encouraged by medical staff, family and friends to undertake physical activity as soon as possible.

KEY WORDS

surgery; breast cancer; posttraumatic growth; mastectomy

ORganizations - Department of Health and Work Psychology, Nofer Institute of Occupational Medicine, Lodz, Poland AUthors' CONTRibution - A: Study design - B: Data collection - C: Statistical analysis - D: Data interpretation .

E: Manuscript preparation · F: Literature search · G: Funds collection

CORRESPONDING AUthor - Aleksandra Andysz, Department of Health and Work Psychology, Nofer Institute of Occupational Medicine, 8 Teresy Str., 91-348 Lodz, Poland, e-mail: andysz@imp.lodz.pl

to Cite this ARticle - Andysz, A., Najder, A., Merecz-Kot, D., \& Wójcik, A. (2015). Posttraumatic growth in women after breast cancer surgery - preliminary results from a study of Polish patients. Health Psychology Report, 3(4), 336-344.

DOI: $10.5114 /$ hpr.2015.52383 


\section{BACKGROUND}

Cancer diagnosis induces a serious crisis in the lives of patients, their families and friends. Despite medical progress and generally good prognosis at early stages of disease, many people still consider such a diagnosis a death sentence. Thus, the struggle with cancer results in extreme stress and a wide range of negative emotions such as fear, anger, or helplessness. Mental consequences, regardless of the type of cancer, involve depression, bipolar affective disorder or anxiety disorders, difficulties in sexual life, negative changes in body image and mental confusion (Fraser, 2003). Sometimes, cancer diagnosis and its treatment cause loss of motivation to participate in social life. One of the most prevalent and troublesome effects of cancer and its treatment is fatigue - affecting every aspect of patients' functioning (Rzepka \& Nowicki, 2010). Also, the disease may also worsen patients' financial situation (Piot-Ziegler, Sassi, Raffoul, \& Delaloye, 2010). Negative physical consequences of surgical treatment include body mutilation and, in the case of radical operations, loss of a breast or both breasts, limitation of mobility of the shoulder girdle and joint on the operated side, pain, discomfort in the chest, significant muscles weakness, changes in the body posture and balance, or lymphedema (Back \& Cieśla, 2009; Kozak \& Smoczyńska, 2012). Negative impacts of a breast operation, especially mastectomy, on mental functioning include fear, changes in body perception (feeling of the breast with cancer as an extraneous body part, grieving after losing a breast), worsening of relationships with other people, decreased quality of sexual life, decreased self-esteem and decreased sense of attractiveness.

Research suggests that some patients after mastectomy suffer from stress recognized as posttraumatic, mainly in the form of intrusions (recurring images, dreams, thoughts or sensations associated with the disease) and avoidance (avoiding thoughts, emotions or conversations about the disease) (Ogińska-Bulik, 2011). O’Connor, Christensen, Jensen, Møller, and Zachariae (2011) found that in a group of women operated on due to breast cancer $(N=3343), 20 \%$ exhibited posttraumatic stress symptoms three months after the surgery. After 15 months they were experienced by $14 \%$ of patients.

\section{POSTTRAUMATIC GROWTH}

The traditional approach in research on the psychological consequences of cancer is expressed in the belief that experience of cancer has a clear negative impact on the patient's mental health and often interferes with treatment. Cancer is commonly treated as a traumatic experience causing a wide range of disturbances such as mood disorders, anxiety or posttrau- matic stress disorder (PTSD) (Gandubert et al., 2009; Shelby, Golden-Kreutz, \& Andersen, 2008; Stafford et al., 2013; Suppli et al., 2014; Vodermaier et al., 2014). Posttraumatic stress disorder as a mental health condition expressed due to trauma and related suffering has frequently been studied in different samples of cancer survivors. However, since the 1980s more attention has been paid to more positive outcomes of human suffering. Nowadays research provides evidence that despite the suffering caused by the diagnosis and treatment of breast cancer, many women experience positive changes in their lives after surviving cancer. The phenomenon of positive changes after traumatic events is described as posttraumatic growth (PTG). There are a few concepts explaining PTG and its possible mechanisms. The oldest, the best known and empirically verified theory was developed in the late 1990s by Tedeschi and Calhoun. They define PTG as the experience of positive change that occurs as a result of the struggle with highly challenging life crises. It is manifested in various ways, including an increased appreciation of life in general, more meaningful interpersonal relationships, an increased sense of personal strength, changed priorities, and a richer existential and spiritual life (Tedeschi \& Calhoun, 2004, p. 1). In other words, PTG relates to coping with particularly difficult life events (accident, assault, natural disaster, loss of somebody, one's own disease or a disease of a close person). It shows a fascinating aspect of human nature - seeking sense and meaning even in the most devastating experiences in life. Posttraumatic growth can be considered as a process itself as well as a consequence of managing traumatic events.

Researchers still discuss the relation between PTG and PTSD which manifests in intense trauma-related re-experiencing, avoidance and arousal symptoms. Cancer patients suffering from PTSD face reoccurring thoughts, pictures and dreams relating to stressful aspects of the disease, make huge efforts to avoid any place/person/thought associated with trauma, and experience an almost constantly high level of psycho-physiological arousal expressed by sleep disturbances, sudden mood switches, and inability to concentrate (Kwakkenbos, Coyne, \& Thombs, 2014; Miller et al., 2014). Recent studies showed that the relationship between stressfulness of traumatic events and PTG is curvilinear (Kleim \& Ehlers, 2009). Not only too little stress but also too extreme stress may result in slight or even no positive changes. On the one hand, the event causing subjectively little stress may not be critical enough to trigger the growth. On the other hand, one may not have enough possibilities to cope with too strong stress. Posttraumatic growth can be considered as a process or a result of managing trauma. Its dynamics is associated with time, and it may appear at different moments following a traumatic event (Bellizzi \& Blank, 2006; Mystakidou et al., 2008).
Posttraumatic growth in women after breast cancer surgery 
Considering the mechanisms of PTG, researchers emphasize the role of the breakdown of beliefs about the world and the role of cognitive processes in reconstructing the new perception of reality (Janoff-Bulman, 2004). Difficult experience often results in reevaluation of one's assumptions about oneself, others and the world. It is not the trauma itself, but the emotional and cognitive response to it and its consequences that constitute factors stimulating PTG (Tedeschi \& Calhoun, 2007). If the process of one's belief system reconstruction after trauma results in more adaptive assumptions about oneself, others and the world, then we can assume that PTG occurred.

Researchers agree that PTG is a desirable phenomenon and it aims at a person's adaptation to consequences of experiencing difficult life events, including health-related trauma.

\section{POSTTRAUMATIC GROWTH OF WOMEN WITH BREAST CANCER}

The results of studies on relations between PTG and posttraumatic stress in women with breast cancer suggest that rather a small percentage of them develop PTSD, while the majority experience PTG (Koutrouli, Anagnostopoulos, \& Potamianos, 2012).

For years researchers have been attempting to identify individual and environmental determinants of PTG in breast cancer patients and survivors. In a recent review, age at the time of diagnosis, education level, economic status, cancer treatment methods, support of others and positive strategies of coping with stress were the most commonly mentioned factors associated with PTG (Koutrouli et al., 2012). According to Weiss (2004), also the presence of a person who fought the disease himself or herself and experienced positive consequences is a strong predictor of PTG. Such a person serves as a model of this process.

It is worth referring to longitudinal studies that are especially valuable because they allow the dynamics of this phenomenon to be captured. In one of them, time since diagnosis, perceived cancer stress and positive reappraisal predicted posttraumatic growth one year after diagnosis (Sears, Stanton, \& Danoff-Burg, 2003). Another study distinguished the following PTG predictors: younger age, search for causes of cancer and expression of inner feelings after the surgery (Manne et al., 2004). That research also showed that the experience of PTG also depends on how a suffering person is supported.

\section{AIM OF THE STUDY}

Despite many foreign studies on PTG among women operated on due to breast cancer, the results remain ambiguous. A well-established model of correlates of
PTG in breast cancer still has not been developed. Moreover, in Poland this issue has not been empirically explored yet.

The aim of our study was to contribute to the development of this topic in Poland and to contribute to the study of PTG worldwide. The research objective was to assess whether Polish women after surgical treatment of breast cancer experience PTG and to identify the area of the greatest psychological changes, as measured with the Posttraumatic Growth Inventory (PTGI).

We posed the following research questions:

1. What percentage of the study group experience PTG, and what is the level of PTG in the study group?

2. Which aspects of PTG (changes in self-perception, changes in relation to others, appreciation of life or spiritual changes) were experienced to the greatest extent in the study group?

3. Do age at the day of survey, age at diagnosis, time since diagnosis, type of surgery, non-surgical methods of treatment, participation in rehabilitation or physical activity significantly differentiate women after breast cancer surgery in experienced PTG?

\section{PARTICIPANTS AND PROCEDURE}

\section{PARTICIPANTS}

The study was a part of a non-profit project titled: "Returning to life - yoga as a method of supporting health, social and occupational rehabilitation of people struggling with cancer". The project was local and was intended for breast cancer patients from Lodz voivodeship. Recruitment to the study was conducted in organizations for breast cancer patients. Participants were informed that the aim of the study was assessment of wellbeing after breast cancer surgery. The participants who decided to exercise yoga were also informed that the effect of yoga on quality of life would be evaluated. Results of comparisons between women who exercised and who did not have been published elsewhere "Returning to life - yoga as a method of supporting health, social and occupational rehabilitation of people struggling with cancer”. Participation in the yoga classes did not affect the results, because the data were collected prior to them and the question on physical activity related to activity undertaken at that time.

Through convenience sampling we gathered self-reported data from 47 women previously operated on due to breast cancer who voluntarily completed the sets of questionnaires.

\section{MEASUREMENTS}

To assess PTG we used a Polish version of the Posttraumatic Growth Inventory (PTGI) (Ogińska-Bulik 
\& Juczyński, 2010). The inventory, originally by Tedeschi and Calhoun (1996), is the most common tool used in PTG research. The Polish PTGI consists of four scales: Self-Perception (Cronbach's $\alpha$ of the original version was .87 ), Relating to Others
(.85), Appreciation of Life (.73) and Spiritual Change (.63) (Ogińska-Bulik \& Juczyński, 2010). Instructions of the PTGI were appropriately reformulated - respondents should strictly refer to the experience of breast cancer. The respondents gave their opinions

Table 1

Characteristics of the studied group in terms of demographic features and aspects associated with the disease and treatment

\begin{tabular}{|c|c|}
\hline Age in years $(M, \pm S D$, min-max $)$ & $57.50, \pm 11.70,27-81$ \\
\hline Age at diagnosis $(M, \pm S D$, min-max $)$ & $51.05, \pm 11.60,25-75$ \\
\hline Years since diagnosis $(M, \pm S D$, min-max $)$ & $6.70, \pm 5.20,1-24$ \\
\hline \multicolumn{2}{|l|}{ Cancer location $-n(\%)$} \\
\hline Left breast & $22(47)$ \\
\hline Right breast & $24(51)$ \\
\hline Both breasts & $1(2)$ \\
\hline \multicolumn{2}{|l|}{ Type of operation - $n(\%)$} \\
\hline Breast conserving surgery & $7(15)$ \\
\hline Mastectomy & $40(85)$ \\
\hline Lymph node dissection $^{\mathrm{a}}$ & $47(100)$ \\
\hline \multicolumn{2}{|l|}{ Type of treatment $-n(\%)$} \\
\hline Chemotherapy & $9(19)$ \\
\hline Hormone therapy & $7(15)$ \\
\hline Chemotherapy, hormone therapy & $13(28)$ \\
\hline Radiotherapy, chemotherapy & $1(2)$ \\
\hline Radiotherapy, hormone therapy & $5(11)$ \\
\hline Radiotherapy, chemotherapy, hormone therapy & $9(19)$ \\
\hline Radiotherapy, chemotherapy, hormone therapy, immunotherapy & $1(2)$ \\
\hline Missing data & $2(4)$ \\
\hline \multicolumn{2}{|l|}{ Participation in rehabilitation $-n(\%)$} \\
\hline Yes & $27(57)$ \\
\hline No & $20(43)$ \\
\hline \multicolumn{2}{|l|}{ Physical activity (fitness, swimming, etc.) $-n(\%)$} \\
\hline Yes & $31(66)$ \\
\hline No & $15(32)$ \\
\hline Missing data & $1(2)$ \\
\hline \multicolumn{2}{|l|}{ Occupational status - $n(\%)$} \\
\hline Working & $15(32)$ \\
\hline Sick leave, rehabilitation allowance, pension & $7(15)$ \\
\hline Unemployed & $2(4)$ \\
\hline Retired & $19(40)$ \\
\hline Missing data & $4(9)$ \\
\hline
\end{tabular}

Postraumatic growth in women after breast cancer surgery

Note. ${ }^{\text {a }}$ category included both women after breast conserving surgery and after mastectomy 
on 21 statements concerning potential changes using a six-point scale: from $0-I$ did not experience this change as a result of the cancer to $5-I$ experienced this change to a very great degree as a result of the cancer (the scale was suitably amended for the purpose of this research). The general index of PTG is a sum of the scores of all items and ranges from 0 to 105 points. The higher the scores, the higher the level of PTG. To make results in PTGI subscales comparable, we used the means from the scores given to items from the scales. In our study the reliability of the tool was .93 for the PTGI and .92 for Self-Perception, .84 for Relating to Others, .61 for Appreciation of Life, and .43 for Spiritual Change. Due to low reliability of indices obtained in our study sample for the last two scales, we decided not to interpret these results.

Age, date of diagnosis, location of cancer, type of surgical and non-surgical treatment, participation in the postoperative rehabilitation and other physical activities (yes/no answers) were controlled in the study. Table 1 presents demographic characteristics of the group.

\section{DATA ANALYSIS}

Data were analyzed with the statistical package SPSS 21. We calculated means, standard deviations, minimum and maximum of the continuous variables and the percentage distribution of PTGI scores. We chose methods that provide reliable results in a small sample. For multiple comparisons of the independent groups we used the Kruskal-Wallis test and for between-group comparisons the Mann-Whitney test. To rate the differences between scores in PTGI scales we used the Friedman test for dependent groups and the Wilcoxon test with Bonferroni correction - the standard level of significance (.05) was divided by the number of comparisons (here: six). In this analysis the adjusted level of significance was .008 - results with $p$ values lower than .008 were considered statistically significant. To determine the strength of the relationship between variables, we calculated Spearman's rank correlation coefficient $(\rho)$.

For age comparisons we distinguished two groups - women aged $\leq 50$ at the day of the survey and

Table 2

Distribution of low, medium and high scores in PTGI

\begin{tabular}{lcc}
\hline \multicolumn{1}{c}{ PTG } & Sten & $\begin{array}{c}\text { Percentage } \\
\text { of participants }(n)\end{array}$ \\
\hline Low & $1-4$ & $34(16)$ \\
Moderate & $5-6$ & $23(11)$ \\
High & $7-10$ & $43(20)$ \\
\hline
\end{tabular}

women aged $>50$. To identify differences in PTG as regards the time since diagnosis, a five-year period, which is commonly recognized when estimating the survival rate in cancer, was taken as a split point.

\section{RESULTS}

The mean general index of PTGI was $63.20( \pm 22.60)$. By converting this index into sten scores according to Polish norms published by Ogińska-Bulik and Juczyński (2010), we distinguished three groups (see Table 2). Forty-three percent of the participants experienced high, 23\% moderate and 34\% low PTG. According to the norms, the mean general score of the study group in PTGI was converted to a sten score of 5 . The median score $(\mathrm{Me}=67)$ was converted to a sten score of 6 (Table 2).

The results in four scales of the PTGI differed significantly $\left(\chi_{(3,47)}^{2}=32.01, p<.001\right)$. The highest scores related to Appreciation of Life, then to Relating to Others. The lowest scores referred to Self-Perception and Spiritual Change scales (see Table 3). The scores of these two scales were comparable $(Z=-0.47, p=.639)$ (Table 3).

The Spearman rank correlation between age at the day of survey and PTGI was not significant for any PTGI scale. We found significant negative correlations between age at diagnosis and the general index of PTG $(\rho=-0.37, p=.012)$, Self-Perception $(\rho=-0.33, p=.029)$, Relating to Others $(\rho=-0.40$, $p=.008)$ and Appreciation of Life $(\rho=-0.39, p=.010)$.

Between-group comparisons showed significantly higher scores of the Appreciation of Life scale among women aged $\leq 50$ at the day of the survey $(n=11)$ than in women aged $>50(n=36)(U=117.50, p=.041)$. Women who declared being physically active at the day of the study had a significantly higher general score of PTGI $(U=118.50, p=.008)$, and higher scores in the scale of Self-Perception $(U=7.28$, $p=.007)$ and in the scale of Relating to Others $(U=108.00, p=.003)$.

To answer the question whether time since diagnosis differentiated respondents in PTG, we compared scores of women diagnosed $\geq 5$ years preceding the survey $(n=21)$ and the scores of women

Table 3

Means and standard deviations of the results of PTGI

\begin{tabular}{lcc}
\hline & $M(S D)$ & $M e$ \\
\hline Appreciation of Life & $3.70(1.00)$ & 4.00 \\
Relating to Others & $3.20(1.20)$ & 3.40 \\
Spiritual Change & $2.80(1.50)$ & 2.50 \\
Self-Perception & $2.70(1.30)$ & 2.90 \\
\hline
\end{tabular}




\begin{tabular}{lc}
\hline \multicolumn{1}{c}{ Item content } & \% of indications \\
\hline Very large changes & 53 \\
I appreciate the value of my life more. & 43 \\
I've changed my priorities as regards what is important in my life. & 43 \\
To a greater extent I notice that I can count on other people's support in difficult & 43 \\
situations. & \\
I've realized that I am stronger than I'd thought. & 45 \\
Large changes & 36 \\
I have learned a great deal about how wonderful people are. & 34 \\
I have more compassion for others. & 34 \\
I accept needing others. & \\
I put more effort into relationships with others.
\end{tabular}

Postraumatic growth in women after breast cancer surgery diagnosed less than 5 years preceding the survey $(n=23)$. The results showed no significant difference $(U=196.50, p=.290)$. There were also no differences in total PTGI score in groups of women who participated in rehabilitation after the surgery and those who did not $(U=228.50, p=.372)$. There were also no differences between groups controlling for the type of surgery $\left(\chi^{2}(3,47)=4.19, p=.242\right)$ and non-surgical method of treatment $\left(\chi^{2}(6,45)=8.31, p=.216\right)$.

Table 4 presents statements of PTGI that concerned very large and large changes as reported by a considerable percentage of participants.

\section{DISCUSSION}

A considerable number of women after breast cancer surgery experienced PTG (Table 2). The general level of PTG was moderate. Considering the PTGI dimensions, we found that as a result of breast cancer $43 \%$ to $53 \%$ of the respondents appreciated life to a great extent, changed their priorities, and became convinced of their strength and the fact that they could count on others (Table 4).

Women aged less than 50 appreciated life significantly more than older women. Additionally, the younger they were on the day of diagnosis, the higher was the level of their overall PTG and the greater was the extent of positive changes in self-perception and relationships with others. This result corresponds with one of the previous studies (Bellizzi \& Blank, 2006). Researchers suggest that the diagnosis of cancer may be less devastating for older people because probably it is not the only (nor the first) critical event in their lives. Perhaps through struggling with difficult life experiences - loss of close people, age-related loss of health, other illnesses - older pa- tients are more able to adjust or less sensitive to the experience of disease (Bellizzi \& Blank, 2006; Mystakidou et al., 2008). Considering the natural, biological order, diagnosis of potentially life-threatening disease at a young age could be more dramatic and less acceptable for an individual. Breast cancer diagnosed at younger age is more aggressive and lethal; thus surviving the disease, "the second chance", is taken with increased appreciation (Cordova et al., 2007; Mystakidou et al., 2008). Moreover, cognitive constructs and emotional responses of younger people (so important in experiencing PTG) may be more susceptible to changes than those of older people (Mystakidou et al., 2008) and more vulnerable to a shattering impact of trauma. For younger people it may be easier to let go of previous beliefs and assumptions about the world and to change their current life. Perhaps the changes occurring after trauma are more spectacular and greater than in the elderly. In our opinion, the observed negative relationship between age and PTG in no way means that for the elderly growth after trauma is unavailable. It suggests that for older adults some other factors would foster the experience of growth after trauma.

The type of operation and treatment were not found to be significant predictors of PTG in this study. The type of treatment is rarely explored in the studies. Exceptions are the studies of Mols, Vingerhoets, Coebergh, and van de Poll-Franse (2009) and Brix et al. (2013). In the first study, a negative relation between PTG and radiotherapy was observed. Unfortunately, the authors did not give any explanation of this result. In the second study, the researchers observed a positive relation between appreciation of life and endocrine treatment. Again, possible mechanisms of this relation were not clearly given. 
The authors drew attention to the fact that endocrine treatment sometimes lasts for years, which may keep suffering women in the role of breast cancer patients for longer, and it may increase the experience of the severity of the disease (Brix et al., 2013). Those authors assumed that this may trigger PTG.

The lack of significant relationship between time since diagnosis, type of operation and treatment and PTG suggests that PTG depends more on perception of the disease than on objective indices of cancer severity (Cordova et al., 2007). It may mean that these are not cancer survival statistics, the stage of cancer or treatment received, but subjective appraisal of threat is a factor fostering PTG. This corresponds to the theory of Calhoun and Tedeschi (1998), who compared the nature of PTG to an earthquake - an event must shake the foundations of a person's world to trigger the process of rebuilding. In our opinion, this result carries an important suggestion for the methodology of future research on PTG in cancer - it seems to us that the question about treatment of cancer brings less to the issue than the question about its subjective burden or efficacy.

The general PTG was not related to postoperative rehabilitation, but it was associated with undertaking other physical activities. Women who reported participating in various forms of physical activities reported higher overall PTG. They also had a better self-perception and relationships with others than those who were not physically active. This may reflect the effect of the physical activity itself - improvement of fitness, body image and well-being. Physical group activities also help to sustain and strengthen the relationships with others and thus contribute to better social functioning. We found only two studies on the relation between PTG and physical activity in oncological patients. Our results are in accordance with one of them. Love and Stabiston (2011) found that physical activity moderated the relation between social support and PTG in young adult cancer patients. In physically active participants, PTG occurred independently from the received social support probably because self-perception, goal adjustment, self-regulation, and schema change (markers of PTG) could result from physical activity itself. This suggests that physical activity catalyzed changes necessary for PTG to occur. In some people, experiencing serious chronic health problems may give the impression that their lives are dominated by the illness and that they are losing control over it. Physical activity may help them to regain control over their lives. However, the other study on physical activity and PTG in women with breast cancer did not show any association (Yang, Baumgartner, \& Baumgartner, 2012). The discrepancy of the results suggests a need for further research.

Because we obtained no satisfactory results concerning the reliability of the scales Appreciation of Life and Spiritual Change in the study group we will not discuss them later in the text. Taking the other two reliable scales into account, we noted that changes in relations with others were significantly larger than changes in self-perception (Table 3). Therefore, PTG in our study group manifested itself in positive changes in relationships. This corresponds to the theoretical framework stating that PTG is a change that raises a person into a more mature level of functioning (Hefferon, Grealy, \& Mutrie, 2009).

Taking the responses to the particular statements of PTGI into account, over $50 \%$ of women from our sample appreciated the value of their lives much more. A considerable percentage $(43 \%)$ of women from the study group also stated that to a very large extent they had changed the priorities in life, noticed that they could count on others and realized their strength.

The strength of the present research is that we included the physical activity in a theoretical model. This variable is rarely studied in oncological patients in the context of PTG. We confirmed previous results revealing a positive relationship between physical activity and PTG (Day, 2013; Love \& Sabiston, 2011).

The simplicity of the theoretical model may be regarded as a limitation of the study. The self-selected (volunteer), convenient and small sample limits the generalizability of the results. The correlational character of the statistical analyses does not allow any conclusions to be drawn about causal relationships between the studied variables. However, it needs to be emphasized that this article presents the results from one of the first Polish studies on this issue, and it presents a topic that is still quite new in Poland. We believe that further research should be carried out in different groups of breast cancer patients, including different variables. Only then can we, as researchers, provide a basis for future comparative analysis, metaanalysis and critical reviews.

\section{FUTURE PERSPECTIVES}

It is necessary to conduct longitudinal research to verify the determinants and dynamics of PTG in Polish patients. It would contribute to the development of a universal model of PTG determinants among breast cancer patients and other people suffering from health-related trauma. Additionally, further research on the role of physical activity in PTG development is recommended. Also a study of women with breast cancer who are socially withdrawn and do not benefit from patient support groups could pose a challenge for future research.

Identifying factors fostering PTG development in patients should become the core of future research, and the results should be taken into consideration by specialists responsible for the treatment and rehabilitation of oncological patients. A holistic approach is 
required - health is not only recovery of the body but also regaining of mental health. Patients who are considered as particularly exposed to negative long-term consequences of their experience (socially withdrawn, not taking part in any physical activity) should be provided with special care.

Although PTG in breast cancer survivors occurs, it does not mean that every patient will experience it (Brix et al., 2013). Expecting suffering people to notice positive sides of their situation and referring to uplifting exemplars of others may exceed their possibilities when raised at an inappropriate moment. For PTG to occur, a person must be ready to answer the fundamental questions related to trauma - Why me?, Why now?, What next?, etc. This readiness requires time, patience and social support. We also suggest paying more attention to such factors as professional medical and social support, religiosity, and coping schemas of the person, which may be critical agents in facilitation of PTG.

We did not obtain satisfactory results concerning the reliability of the two PTGI scales Appreciation of Life and Spiritual Change. Further studies on the psychometric properties of the Polish PTGI are required. Hefferon et al. (2009) suggested that the increase of body awareness and responsibility for one's own health also relate to people who experience health-related trauma. However, this dimension has not been included in any questionnaire used in research so far. Therefore we propose to focus on the development of the measurement of this aspect of PTG in future research.

\section{CONCLUSIONS}

The present results confirm that PTG is experienced by a considerable percentage of women diagnosed with breast cancer, who have undergone surgical interventions. The consequences of suffering from a severe disease such as breast cancer may include positive changes concerning self-perception and improvement of relationships with others.

Searching for correlates and determinants of PTG is of great significance, and thus we consider our results on physical activity and PTG as worth emphasizing. Because women who at the time of the survey were physically active showed a higher level of posttraumatic growth, we recommend that women after breast cancer surgery be encouraged by medical staff, family and friends to undertake physical activity as soon as possible.

\section{ACKNOWLEDGMENTS}

We would like to thank Marzenna Lewandowska, Dorota Pasińska-Swędrowska and Elżbieta Reguła,
Kamilla Sierocka and Zofia Włodarczyk for their help in conducting the study.

\section{References}

Bellizzi, K. M., \& Blank, T. O. (2006). Predicting posttraumatic growth in breast cancer survivors. Health Psychology, 25, 47-56.

Brix, S. A., Bidstrup, P. E., Christensen, J., Rottmann, N., Olsen, A., Tjønneland, A., Johansen, C., \& Dalton, S. O. (2013). Post-traumatic growth among elderly women with breast cancer compared to breast cancer-free women. Acta Oncologica, 52, 345-354.

Bąk, M., \& Cieśla, S. (2009). Ocena zaburzeń postawy ciała kobiet po radykalnej amputacji z jednoczasową rekonstrukcją piersi [Assessment of postural disorders in women after radical mastectomy followed by immediate breast reconstruction]. Fizjoterapia, 17, 30-37.

Calhoun, L. G., \& Tedeschi, R. G. (1998). Posttraumatic growth: Future directions. In: R. G. Tedeschi, C. L. Park, \& L. G. Calhoun (eds.), Posttraumatic growth: Positive changes in the aftermath of crisis (pp. 215-238). Mahwah, New Jersey: Lawrence Erlbaum Associates.

Cordova, M. J., Giese-Davis, J., Golant, M., Kronenwetter, C., Chang, V., \& Spiegel, D. (2007). Breast cancer as trauma: Posttraumatic stress and posttraumatic growth. Journal of Clinical Psychology in Medical Settings, 14, 308-319.

Day, M. C. (2013). The role of initial physical activity experiences in promoting posttraumatic growth in Paralympic athletes with an acquired disability. Disability \& Rehabilitation, 35, 2064-2072.

Fraser, M. (2003). Psychological Consequences of Cancer and Their Management. Current Medical Literature: Breast Cancer, 15, 61.

Gandubert, C., Carrière, I., Escot, C., Soulier, M., Hermès, A., Boulet, P., Ritchie, K., \& Chaudieu, I. (2009). Onset and relapse of psychiatric disorders following early breast cancer: a case-control study. Psycho-Oncology, 18, 1029-1037.

Hefferon, K., Grealy, M., \& Mutrie, N. (2009). Posttraumatic growth and life threatening physical illness: A systematic review of the qualitative literature. British Journal of Health Psychology, 14, 343-378.

Janoff-Bulman, R. (2004). Posttraumatic growth: Three explanatory models. Psychological Inquiry, 15, 30-34.

Kleim, B., \& Ehlers, A. (2009). Evidence for a curvilinear relationship between posttraumatic growth and posttrauma depression and PTSD in assault survivors. Journal of Traumatic Stress, 22, 45-52.

Koutrouli, N., Anagnostopoulos, F., \& Potamianos, G. (2012). Posttraumatic stress disorder and post-
Posttraumatic growth in women after breast cancer surgery 
traumatic growth in breast cancer patients: a systematic review. Women \& Health, 52, 503-516.

Kozak, D., \& Smoczyńska, M. (2012). Psychofizyczna rehabilitacja pacjentek w wieku podeszłym leczonych operacyjnie z powodu raka piersi [Psychophysical rehabilitation of elderly female patients after breast cancer surgery]. Hygeia, 47, 139-144.

Kwakkenbos, L., Coyne, J. C., \& Thombs, B. D. (2014). Prevalence of posttraumatic stress disorder (PTSD) in women with breast cancer. Journal of Psychosomatic Research, 76, 485-486.

Aleksandra

Andysz,

Anna Najder, Dorota

Merecz-Kot, Aleksandra Wójcik

Love, C., \& Sabiston, C. M. (2011). Exploring the links between physical activity and posttraumatic growth in young adult cancer survivors. PsychoOncology, 20, 278-286.

Manne, S., Ostroff, J., Winkel, G., Goldstein, L., Fox, K., \& Grana, G. (2004). Posttraumatic growth after breast cancer: Patient, partner, and couple perspectives. Psychosomatic Medicine, 66, 442-454.

Miller, A. B., Wall, C., Baines, C. J., Sun, P., To, T., \& Narod, S. A. (2014). Twenty five year follow-up for breast cancer incidence and mortality of the Canadian National Breast Screening Study: randomised screening trial. British Medical Journal, 348, g.366. DOI: 10.1136/bmj.g366

Mols, F., Vingerhoets, A. J. J. M., Coebergh, J. W. W., \& van de Poll-Franse, L. V. (2009). Well-being, posttraumatic growth and benefit finding in longterm breast cancer survivors. Psychology and Health, 24, 583-595.

Mystakidou, K., Tsilika, E., Parpa, E., Kyriakopoulos, D., Malamos, N., \& Damigos, D. (2008). Personal growth and psychological distress in advanced breast cancer. The Breast, 17, 382-386.

O’Connor, M., Christensen, S., Jensen, A. B., Møller, S., \& Zachariae, R. (2011). How traumatic is breast cancer? Post-traumatic stress symptoms (PTSS) and risk factors for severe PTSS at 3 and 15 months after surgery in a nationwide cohort of Danish women treated for primary breast cancer. British Journal of Cancer, 104, 419-426.

Ogińska-Bulik, N. (2011). Rola prężności psychicznej w przystosowaniu się kobiet do choroby nowotworowej [The role of resiliency in adjustment to cancer in women]. Psychoonkologia, 1, 16-24.

Ogińska-Bulik, N., \& Juczyński, Z. (2010). Rozwój potraumatyczny - charakterystyka i pomiar [Posttraumatic growth - characteristic and measurement]. Psychiatria, 7, 129-142.

Piot-Ziegler, C., Sassi, M. L., Raffoul, W., \& Delaloye, J. (2010). Mastectomy, body deconstruction, and impact on identity: a qualitative study. British Journal of Health Psychology, 15, 479-510.

Rzepka, K., \& Nowicki, A. (2010). Fatigue among breast cancer patients. Wspótczesna Onkologia-Contemporary Oncology, 14, 321-325.

Sears, S. R., Stanton, A. L., \& Danoff-Burg, S. (2003). The yellow brick road and the emerald city: ben- efit finding, positive reappraisal coping and posttraumatic growth in women with early-stage breast cancer. Health Psychology, 22, 487-497.

Shelby, R. A., Golden-Kreutz, D. M., \& Andersen, B. L. (2008). PTSD diagnoses, subsyndromal symptoms, and comorbidities contribute to impairments for breast cancer survivors. Journal of Traumatic Stress, 21, 165-172.

Stafford, L., Judd, F., Gibson, P., Komiti, A., Mann, G. B., \& Quinn, M. (2013). Screening for depression and anxiety in women with breast and gynaecologic cancer: course and prevalence of morbidity over 12 months. Psycho-Oncology, 22, 2071-2078.

Suppli, N. P., Johansen, C., Christensen, J., Kessing, L. V., Kroman, N., \& Dalton, S. O. (2014). Increased Risk for Depression After Breast Cancer: A Nationwide Population-Based Cohort Study of Associated Factors in Denmark, 1998-2011. Journal of Clinical Oncology, 32, 3831-3839.

Tedeschi, R. G., \& Calhoun, L. G. (1996). The Posttraumatic Growth Inventory: Measuring the positive legacy of trauma. Journal of Traumatic Stress, 9, 455-471.

Tedeschi, R. G., \& Calhoun, L. G. (2004). Posttraumatic Growth: Conceptual Foundations and Empirical Evidence. Psychological Inquiry, 15, 1-18.

Tedeschi, R. G., \& Calhoun, L. G. (2007). A Clinical Approach to Posttraumatic Growth. In: P. A. Linley \& S. Joseph (eds.), Positive psychology in practice (pp. 230-248). Warsaw: PWN.

Vodermaier, A., Linden, W., Rnic, K., Young, S. N., Ng, A., Ditsch, N., \& Olson, R. (2014). Prospective associations of depression with survival: a population-based cohort study in patients with newly diagnosed breast cancer. Breast Cancer Research and Treatment, 143, 373-384.

Weiss, T. (2004). Correlates of posttraumatic growth in married breast cancer survivors. Journal of Social and Clinical Psychology, 23, 733-746.

Yang, D., Baumgartner, R. N., \& Baumgartner, K. B. (2012). Posttraumatic Growth and Physical Activity Among Hispanic and Non-Hispanic White Long-Term Breast Cancer Survivors. American Journal of Epidemiology, 175, S104. 